\title{
Elements of Research Based Pedagogical Tools for Teaching Science
}

\author{
Z.N. Kashmiri ${ }^{1 *}$ and A.S. Masram ${ }^{2}$ \\ ${ }^{1}$ Department of Zoology, Dada Ramchand Bakhru Sindhu Mahavidyalaya, Nagpur, India \\ ${ }^{2}$ Department of Zoology, L.A.D. and Smt. R.P. College for Women, Nagpur, India \\ "Corresponding author: kashmiri_zeenat@yahoo.com
}

Received: 25-09-2020 Revised: $13-11-2020$

Accepted: 07-12-2020

\begin{abstract}
Now-a-days computers and internet provides oceans of information to the learners at their fingertips. Therefore, to maintain the pace with the present generation of learner who are digital natives, the real challenge is faced by the teacher. The conventional role of teacher to provide information has shifted to a role of mentor or a facilitator. Teaching science with conventional method at Higher Education Institutes (HEIs) often involves lectures being given to a large group of students accompanied by practicals, workshops and with some independent study. But teaching science in the $21^{\text {st }}$ century must include teaching them to think, acquire, solve the real life problem and make knowledgeable conclusions. It is important to inculcate the qualities like inquiry and critical thinking amongst students, as these skills are useful to students from school to career. Research-Based Pedagogical Tools (RBPTs) are research as a pedagogical tool to build an environment for the students which promotes learners to think beyond the textbooks and do some research to understand the concept in more concrete way. In this paper we will discuss about elements of research-based pedagogical tools for teaching science at higher educational institutes.
\end{abstract}

$\overline{\text { Keywords: Research-Based Pedagogical Tools, Higher Education Institutes, Inquiry, Critical thinking. }}$

Science from the Latin word Scientia, meaning "knowledge" (Douglas, 2014) is a systematic enterprise that builds and organizes knowledge in the form of testable explanation and predictions about the universe (Welson, 1999 and Heilbron, 2003). It involves systematic inquiry, data collection on the basis of principles, theories and observation based on knowledge. Science teaching involves creating a learning environment wherein each learner deals with problem situations, engages in reflection within one self and with others, looks for concrete evidences and thereby construct one's own knowledge (mooKIT).

Wang and Reeves (2003) point out that many educators, as well as people in the general public, believe that computers and the internet are simply much more powerful educational tools, therefore teaching science with traditional methods would not be appropriate for today's learner. Although large-scale success stories in real, school-based applications of educational technologies have been exceedingly rare (Cuban, 2001).

According to theory of social facilitation, the people often perform better in the presence of others than alone (Cook, 2001). Working in groups is thought to better enhance students' learning perceptions, problem solving skills and overall learning abilities than learning alone (Hiltz et al. 1999). Blending research with teaching can acts as an effective vehicle for developing true scientific understanding,

How to cite this article: Kashmiri, Z.N. and Masram, A.S. (2020) Elements of Research Based Pedagogical Tools for Teaching Science. Educational Quest: An Int. J. Edu. Appl. Soc. Sci., 11(4): 189-192.

Source of Support: None; Conflict of Interest: None क्? 
vital knowledge for the world community now and in the future (mooKIT). Research-based pedagogical tools (RBPTs) are one of such methods in which students work in a groups to find the solution of real life problems with scientific temperament. In this paper we will discuss about elements of ResearchBased Pedagogical Tools (RBPTs) for teaching science at Higher Education Institutes (HEIs).

\section{Research-Based Pedagogical Tools}

Research-Based Pedagogical Tools (RBPTs) are pedagogical tools used to infuse research with teaching. RBPTs have many other name like research-based learning (RBL), problem-based learning (PBL), inquiry based learning (IBL), project based learning (PBL) and learning by doing, cooperative learning, science in the real world, etc. The main purpose of the RBPTs is to provide learner centric environment in the classroom, providing exercise wherein the student is engaged in research activity to develop the knowledge of a particular topic in inquiry mode. They are pedagogical tools and not the research. They are primarily used to teach science and mathematics although authentic research occur. The RBPTs develops research skills and deep content understanding among the students and acquired a relevant domain knowledge. RBPTs focus on process of science rather than routine for conceptual understanding. They includes methods and essential elements of logic, critical thinking, interpretation, analysis and help to imbibe problem solving, research skill with domain knowledge. (mooKIT and handbook STEM workshop).

During RBPTs students to go beyond the core content found in textbooks and consider the implications of real-world research evidence, data, and interpretations they analyze either virtually or in the field. Students are encouraged to look at both local and global situations and to engage intelligently in public debate about matters of scientific and technological concern. The role of teacher during the process of RBPTs is of facilitator, all the other activities are to be carried out by the students. Following are some of the reasons to use inquiry based learnings in the classroom teaching (teachthought.com):

1. Nurture student passions and talents

2. Empower student voice and honorstudent's choice.
3. Increase motivation and engagement.

4. Foster curiosity and a love for learning.

5. Teach grit, perseverance growth mindset and self-regulation.

6. Make research meaningful and develop strong research skills.

7. Deepen understanding to go beyond memorizing facts and content.

8. Fortify the importance of asking good questions.

9. Enable students to take ownership over their own learning and to reach their goals.

10. Solve the problems of tomorrow in the classroom today.

\section{Elements of RBPTs}

There are five elements of research-based pedagogical tools. They are Recognize, Require, Refines, Reward and Report (Fig. 1). The success of the RBPTs are rest on proper consideration of these 5Rs while planning RBPTs. The detail description of the elements are given below.

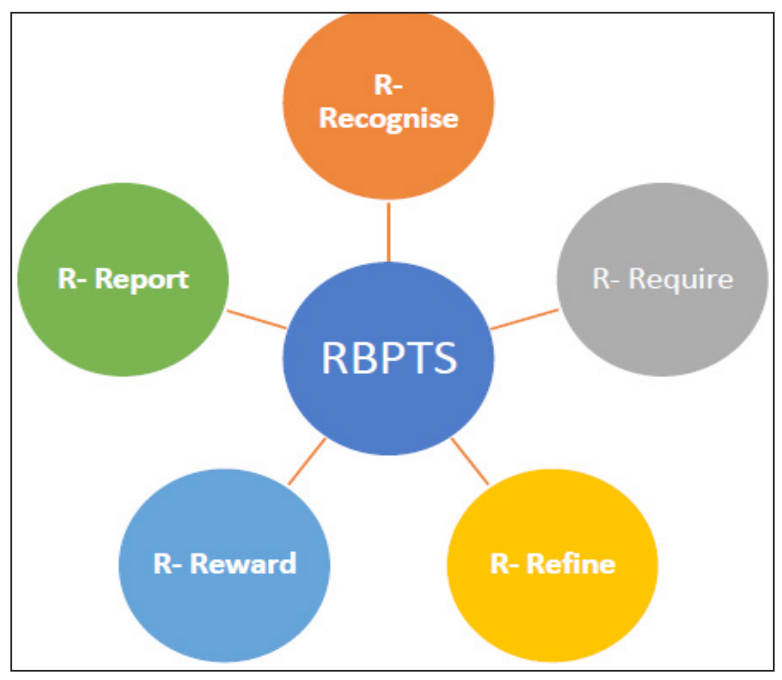

Fig. 1: Elements of RBPTs (Curtesy: mooKIT)

\section{R- Recognize}

The first element of the RBPTs is Recognize i.e. to recognize the research problem. The problem selected for RBPTs should have clear link to content that is relevant to student's curriculum and embedded in a realistic context which will allow students to select and deploy relevant scientific understanding to solve the problem. 
While planning for RBPTs for students the main ingredient should be research, the student should do some research to attain the solution to the posed problem. For this the context of the research problem should be provocative, Authentic and Integrated (Handbook, SETM workshop on RBPTs), this is the most important step in RBPT. Presenting science knowledge in meaningful contexts eases the complexity normally attendant upon transferring information learned in classroom to non-classroom contexts (Cavagnetto, 2010). The provocative context means it should excite interest, raise questions and link to a learning objectives of the problem and based on previous knowledge to the students, the context should be authentic so that we can apply it to life and integrated with the knowledge about science and working scientifically (Handbook, SETM workshop on RBPTs). Thus Research involves a knowledge base, effort and skill, critical thought process and reflection.

\section{R- Require}

The second element of RBPTs is Require. The second R-Require is the most important element while developing RBPT. It is important to know is research really required to solve the problem. Sometimes students frame a problem which may be answered only by reading the text book or maybe answered by surfing the search engine there is no requirement of research for such problems (mooKIT). After selecting the problem for research the students now have to find out the solution through research. Only RBPTs require research - a strategic step into the unknown rather than simple recall or identification.

\section{R-Refine}

The third element of RBPTs is Refine. This step is a proof reading of the design which is framed for the students. Refine at right stage is needed so that the quality of research work sustained. In view of learning objectives we can refine the contents. It triggers the ability and aptitude of the students in a right way, the skills required can get polished and improvised by integration of this R (mooKIT).

\section{R-Reward}

This is the fourth element of RBPTs. Rewards are to assess knowledge, skill and attitude achieved by the students during the process of research. For this learning outcomes are clear to the instructor and students. The assessment may be formative or summative. This test assesses the success of the activity. One can check the learning outcome of the activity by conducting a test, analyses the results in terms of the understanding of the students. The assessment may be self-assessment, peer assessment, staff assessment or computer based assessment. Students learning deeper understanding and high order cognitive skills (STEM workshop).

\section{R-Report}

The fifth element of the RBPTs is Report. Since RBPTs study is a kind of research, the report of the research outcome is mandatory. Research outcome may be in the form of written blog, newspaper article, poster, presentation in the seminars, research publications, collection of the material and patents, etc.

Thus, RBPTs are pedagogical tools that recognize, require, refine, reward and report the research activity. Through RBPTs, students develop their research experience, skills and acquire relevant domain knowledge. PARAO i.e. problem, activities, resources, assessment and output are the components involved in RBPTs. (Fig. 2).

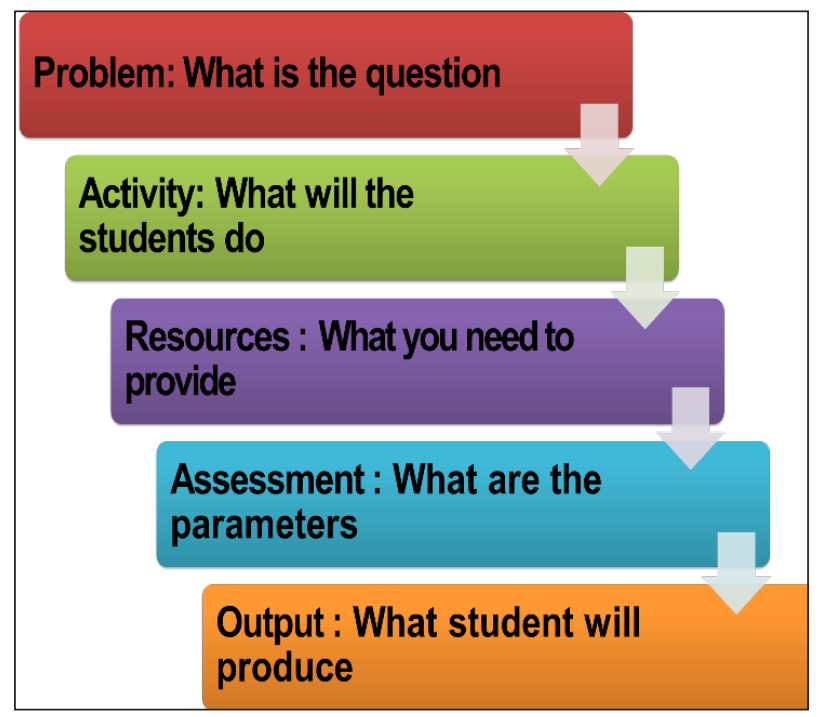

Fig. 2: Steps involved in RBPTs (Curtesy: STEM workshop, IISER, Pune)

RBPTs involves following steps such as to set a problem based on curriculum for the research, to decide learning objectives i.e. what students should achieved after doing research, to plan different activities which is appropriate to solve the problem, 
to provide resources i.e. what the students needed to do research, assessment to assess knowledge, skill and attitude achieved by the students during the process of research and output i.e. the result of the research to be published in the form of blog, newspaper article, presentation, poster, etc. It is important to concentrate on 5Rs and PARAO during planning of RBPTs for its attainment.

\section{CONCLUSION}

In the era of ICT, when every information is available on the fingertips, conservative classroom teaching i.e. lecture method or chalk duster method is going through a transition period and to face this new change, as a teacher one must evolve new techniques and tools of the teaching. In regard of above view RBPT facilitates the new teaching tool without using computer technology. Research Based Pedagogical Tools proves to be a very useful tools which can be used to teach a topic for the better understanding of the students. This tool involves more number of students and creates interest, enthusiasm, leadership quality, communicative skills, and applicability knowledge among the students. RBPTs helps to inculcate the research attitude and firsthand experience, enhances critical thinking, analytical skills, decision making, data interpretations and troubleshooting. This method is useful to apply the knowledge to solve real life problems.

\section{ACKNOWLEDGEMENTS}

The Authors would like to thank to the entire COESME Team at IISER, Pune and experts from Sheffield Hallam University, UKfor training in RBPTs during Regional and NationalSTEM Workshop on Research Based Pedagogical Tools held at Amravati and Jaipur respectively organized by IISER, Pune.

\section{REFERENCES}

Cavagnetto, A.R. 2010. Argument to foster scientific literacy: A review of argument interventions in $\mathrm{K}-12$ science contexts. Review of Educational Research, 80(3): 336-371.

Cook, R. 2009. Social psychology in project management. 2001. Retrieved November 20, from http://www.pmforum.org/ library/papers/ pmpsych1.htm.

Cuban, L. 2001. Oversold and underused: Computers in the classroom. Cambridge, Massachusetts: Harvard University Press.

Douglas, H. 2014. Science, Online Etymology Dictionary.

Heilbron, J.L. 2003. Preface, The Oxford Companion to the History of Modern Science. New York: Oxford University Press, pp. vii-x.

Hiltz, S.R., Coppola, N., Rotter, N. and Turoff, M. 1999. Measuring the importance of collaborative learning for the effectiveness of ALN: A multi-measure, multi-method approach. Journal of A synchronous Learning Networks, 4: 103-125.

RBPT handbook- provided by trainers, Sheffield Hallam University and ISSER Pune, Funded under NewtonBhabha, DBT and MHRD sponsored PMMMNMTT scheme.

Wang, F. and Reeves, T.C. 2003. Why do teachers need to use technology in their classrooms? Issues, problems and solutions. Computers in the Schools, 20(4): 49-65.

Wilson, E.O. 1999. The natural sciences, Consilience: The Unity of Knowledge (Reprint ed.). New York, New York: Vintage, pp. 49-71.

\section{Web links}

http://resources.glos.ac.uk/ceal/; http://resources.glos.ac.uk/ tli/prsi/current/ugresearch/index.cfm;

https://courses.mookit.in/course/rbpts

https://www.teachthought.com/critical-thinking/10-benefitsof-inquiry-based-learning/

www.warwick.ac.uk/fac/soc/sociology/research/cetl/

www.heacademy.ac.uk 